\title{
FAMILY QUALITY OF LIFE AND NURTURING THE SIBLING RELATIONSHIP
}

\section{Nicole Kyrkou}

\begin{abstract}
Research that gauges family quality of life in families that include a child with a disability has often focused on the relationship between parents and the child, but in doing so they underestimate the importance of the sibling relationship: siblings are in each other's lives generally for a much longer period of time than parents are. The sibling relationship is not intrinsically positive or negative, but it is a dynamic and critical bond; from it children can learn to understand and advocate for themselves and each other in the context of the disability. The sibling relationship is a lifelong one. Nurturing it in the early stages of development will not only support family quality of life, but will set the foundation for healthy adult sibling relationships that can create positive outcomes for all members of the family. The important aspects of nurturing the sibling relationship are considered from the viewpoint of both sibling and parent. The assumptions that inform sibling relationships are discussed, and suggestions for nurturing them are provided.
\end{abstract}

Keywords: siblings, disability, family dynamics, quality of life

Nicole Kyrkou MSc is a Developmental Educator and a medical student at Flinders University, Sturt Road, Bedford Park 5042, South Australia, Australia. Email: kyrk0002@flinders.edu.au 
My purpose in writing this article is to bring together decades of sibling wisdom cultivated through personal experience, connecting with other siblings, and talking with their families. My own experience as a sibling led into volunteering and then working in the disability field within a range of services, from case management for future planning to provision of a crisis response; and across a range of disability experiences, from intellectual and physical disability to complex health and palliative care.

Quality of life research shows that families without a child with a disability have higher levels of satisfaction across all domains in comparison to families where there is a child with a disability (Brown, MacAdam-Crisp, Wang, \& Iarocci, 2006). In the growing body of research that focuses on the perspective of siblings of children with a disability, there is evidence to suggest both positives and negatives, as well as a general understanding from siblings of the family dynamic and how having a sibling with a disability has influenced this (Luijkx, van der Putten, \& Vlaskamp, 2016; Wofford \& Carlson, 2017). When a child in the family has a chronic health condition, the health of a sibling without disability is often overestimated by parents in comparison to the siblings's own perceptions (Limbers \& Skipper, 2014), which can have an impact on the siblings and their relationship with each other. Because of the tendency to overestimate, it is important to draw on first person accounts when considering the sibling perspective.

The main focus of this article is to discuss some of the practical aspects of the sibling relationship through the major developmental stages of early childhood, school years, adolescence, and the shift into adulthood. This includes the practical aspects of the sibling experience through a range of perspectives including communication, advocacy, and navigating social situations.

\section{The Sibling Experience}

There is no single best way to nurture the sibling relationship. The perception that some best approach must exist will ultimately lead to unhelpful feelings of guilt, failure, and inadequacy. No two families will have the same experience of disability or the same expectations of what they need to achieve for family quality of life. For this reason, one must be cautious in making comparisons between families: we do not always see the private day-to-day worlds in which they live. Parents of a child with a disability can often see another family's situation as harder than their own and be quite dismissive of the difficulties of their personal circumstances.

As noted above, it is important to consider not just parents' perspectives but also those of siblings. Although these perspectives will change over time they add another layer of information and context for decision-making within the family. Nurturing the sibling relationship is not about cramming additional stress into an already jammed day; instead, it can offer a bit of 
breathing space for parents and a chance for siblings to just be together and hang out over a shared experience.

I make the point that sibling relationships are not inherently either good or bad because so much of what is said about sibling relationships puts them into one of these categories. This takes many forms: for example, an adult supporting her sister in hospital might regularly hear from nurses that she is a good sister for helping out and giving her mother a break from sitting in the hospital. The remark is meant well, but it leaves the impression that by failing to take the commended actions she could be considered a bad sister. This connects with the assumptions that can pervade sibling conversations and add an unnecessary and possibly detrimental expectation into a sibling's perspective. In any sibling dynamic there is a constant cycling of both positive and negative experiences, as is characteristic of most enduring relationships.

How siblings learn to interact with each other and be around each other is shaped by the stories parents create about their interactions. The verbal and non-verbal messages parents use can be powerful in shaping the experiences of siblings. For example, when a child with a disability is being bathed by the mother and a sibling comes in to help by getting the towels out, the sibling wants to help and engage in the activity, but the mother might discourage them from helping because she does not want to burden the sibling with the caring role. If the sibling does not understand the mother's motives, she or he may feel unwanted or unhelpful. When the sibling does not know how they fit into the family dynamic, it can cause resentment. When there is a child with high support needs, involving a sibling in personal care activities can lead to meaningful interaction with the sibling as well as the parent.

While the research can provide themes, and the parents will have their own perspectives, it is important for the sibling voice to be heard. When siblings are close in age they can also offer unique insights into the factors relevant for the child with a disability. Parents will sometimes report that the child with a disability will respond more positively to the sibling making a request of them than they would if the request came from one of the parents.

\section{Developmental Stages}

There are some important milestones to consider as the sibling relationship progresses through the early years, schooling, adolescence, and into adulthood. I discuss each of these areas in relation to the factors a family might need to consider for the sibling relationship, while taking account of the reality that there can be more than two siblings, each at a different stage of development.

\section{Early Years}

The early years in the life of a child with a disability are associated more with questions than answers not just for parents, but for siblings as well: questions about trying to confirm a diagnosis or just trying to understand the nature of the child's disability. It can be a time of high 
expectations in trying to find a cure or fix, and of deep devastation upon realising there is not going to be one. While some families may describe feeling that they are on a merry-go-round, others may feel like hostages on a roller-coaster ride. Regardless of which ride it feels like, families still need to feel empowered to make choices about how much time and energy should go into the needs arising from their child's disability as opposed to the family's other needs. The balance will depend in part on how much crossover these needs have. At one extreme, there are families who will take on extensive therapy sessions and allocate most of their free time to disability needs, and at the other extreme there are families that focus on disability as little as possible. Everyone else stands somewhere along the continuum between them. The question each family must decide for itself is how much it can take on as a family.

How can the sibling relationship be nurtured in the early years? By giving children knowledge of what is happening with their sibling at an age-appropriate level and in the context of their own development. This needs to be treated as an ongoing conversation that will start early and continue through to adolescence based on the child's interest and priorities. If the only question a sibling has is whether their sibling with a disability can play cricket with them, the conversation can start from there. A key passage may occur when the typically developing sibling overtakes the sibling with a disability, as this can be a time that generates questions for the siblings or gives them their first insights into their more pervading differences.

When it comes to therapy, siblings can often be included in play sessions and can have supported time to develop their play skills. There are also the unscripted times that siblings can just be around each other and interact however they prefer. These times can be squeezed out by too many planned activities, leaving some siblings feeling excluded or isolated from one another. Awareness that professionals are involved can lead some children to shy away and feel that they do not know how to be with a sibling. One woman spoke of her discomfort at being around her sister with multiple disabilities, and in particular that her sister was always dribbling. Decades later she reported feeling a sense of jealousy that her own children would naturally climb into her sister's lap for a cuddle and yet she could not be that close to her. Had her discomfort been openly discussed with her when she was a child, it might perhaps have become a non-issue. When parents can create an open, non-judgemental atmosphere, siblings will feel free to ask all their questions, which will not only help parents understand their perspectives, but can also help scaffold a successful sibling relationship.

\section{What is Normal?}

As the second child in the family, I was never really aware of there being a difference in our sibling experience in comparison to other families. Nothing screamed out that this was different or that it did not match up to typical sibling experiences. Being asked how it feels to be a sibling is rather like being asked how I might feel about having two arms. The question of how it feels to have a sibling without a disability is one the questioner has probably never really had to consider, or cared to. 
International Journal of Child, Youth and Family Studies (2018) 9(4): 75-87

"What is it like to be a sibling?" This is a question I have heard many times over the years and often without explicit reference to the sister with disability who makes me "that" sibling. Somehow the reference to disability has just been assumed, as if "sibling" has become a word we associate with having another kind — an "other" kind — of brother or sister in the family.

The context of having a sibling with disability is taken for granted when you grow up knowing nothing else. Even without shared verbal communications, siblings develop an understanding and appreciation of each other through sharing time together in their day-to-day lives. The relationship is maintained with time together and by the support of parents knowing when to step in and support and when to let the children work through a situation together. The siblings' interactions need to be considered within the family context of what is realistic for the circumstances. A child with a disability who spends most of their time in bed due to medical needs has very different opportunities to interact with their siblings than a child with an intellectual disability who is ambulant and can move around in the home independently.

\section{Sibling Expectations}

Siblings and their relationships are an important part of family quality of life. There is a lifelong connection that can be nurtured and explored for siblings that is unlike any other human relationship. The form that the sibling relationship takes is dependent on the family context, the experience of disability, and the personal perspectives of family members.

The everyday language we use reflects our underlying assumptions and this can have an impact on the sibling bond. If a child with a disability were to suddenly cry out in pain, a parent might respond in many different ways: for instance, with curiosity ("Show me what happened.") or with accusatory statements ("What did you do to your sibling?"). These approaches may have very different impacts for the siblings and their relationship. When assumptions shape language, they can lead to communications that show limited understanding for the family dynamics when there is a child with a disability and can prevent the siblings from sharing the experiences of their reality. Being told how well they cope with their brother or sister's behaviour can close off the sibling's option for sharing their own experience of the behaviour. In my case, my reality shifted not because of my sister or any sense of her difference but because of other people's reactions to her, and their difficulty in seeing her. I understood my sister, but it became clear to me very early on in my life that other people did not seem to have the same capacity or inclination.

As a preschooler, I remember standing in the backyard with my mother, my sister, and a camera crew. This was not our usual afternoon activity! The crew asked me to play with my sister and my expression must have been hilarious: it would have been one part wonder, two parts annoyance that they did not understand the problem with that request. At that time my sister enjoyed pacing, with an occasional run while shrieking, and usually while holding, scrunching, and twirling an item or two that she had chosen. This was not a two-person activity. How was that going to create a play moment on film between preschoolers? Just then my sister 
International Journal of Child, Youth and Family Studies (2018) 9(4): 75-87

ran off into the yard as she liked to do and the crew, realising the opportunity was slipping away, asked me to run after her. So I ran after her and they got their shot. Luckily for the crew my sister did love the swing and from an early age had learnt the phrases "push me" and, when circumstances necessitated it, "push please". So after the footage of our run into the backyard, the rest of the film showed us on a seesaw swing looking like typical kids playing in their backyard. The film session resulted in a media misdirection that would make all appear normal to an uninformed observer.

Even at my young age it struck me how odd that request was, because my sister and I did not "play", but really only gravitated around each other. When, however, I was asked to run after my fleeing sister - well, that I could do. With a sister noted for absconding, and for getting out of the escape-proof child car seat with its five-point harness, chasing her was a well-honed skill.

\section{Balancing Sibling Needs}

This can be an area that creates a lot of unnecessary guilt and angst. Siblings are usually well able from a young age to understand that their sibling with a disability needs more time and attention to accomplish things that they themselves can do independently. A sibling with disability requiring more personal care or supervision can take parental time and attention away from other siblings. Making sure that each sibling has some quality time with parents can keep this in balance. This does not require grand gestures. It can consist simply of sharing household activities, of having a chat while washing the dishes or walking the dog.

Comparisons across families with regard to balancing sibling needs must be approached very cautiously, as their experiences may be very different. Consider the contrast between the experiences of a family with a child who absconds from home versus one with a child who is likely to fall over, or those of a family with a child with disability who will happily play in their own space for hours without interruption versus one whose child demands ongoing adult attention. How a family creates quality time needs to fit within their own context and make sense for them. There are no hard and fast rules, so families need to be empowered to create the family dynamic that best serves all members, both parents and siblings.

\section{School Years}

The school years start with the decision to either have the siblings attend school together or give them space at different schools. Geography might limit this choice, as well as the need to consider a special education option. There might even be times that a school transfer needs to be considered for reasons unrelated to the disability. Siblings in the same school can be a positive experience in developing a social support network within the school, helping to build the sibling relationship, and fostering greater disability awareness in the local school community.

Unfortunately, having a sibling with disability in the same school can also burden the sibling with additional caring responsibilities and detract from their own education and social 
International Journal of Child, Youth and Family Studies (2018) 9(4): 75-87

networks. Siblings have been called upon to respond to a child's difficult behaviour, provide health support, provide yard duty when a teacher has forgotten, or accompany their sibling in the ambulance. If siblings are going to the same school, there needs to be a shared understanding of expectations among teachers, parents, and the siblings themselves.

In the school years, teasing and bullying behaviours can present. Talking with the siblings about what experiences they may encounter can support them to respond if they find themselves in such a situation. If the children have not been exposed to teasing or bullying personally, referencing movies, media, or other relatable incidents can be useful for starting the conversation.

\section{Sibling Self-Advocacy}

It is through choices and activities in the family context that siblings will learn to advocate for themselves and each other. These opportunities help set the foundation for how siblings will relate to each other, so spending the time early on to develop and reinforce these skills will be beneficial. Interactions should be shaped in such a way that they can be transitioned into later life stages as the siblings mature. Think about how the children are interacting now and how those same interactions would look if they were ten or twenty years older. Behaviours that do not create any concern from this vantage point are probably worth reinforcing. Setting children up with a skill for life can minimise the amount of relearning and strengthen the sibling relationship. For example, some of the language siblings use when asking for the toilet or bathroom is appropriate at any age, but saying that they "need to use the potty" has limited appropriateness. The same consideration needs to be given to physical interactions between siblings: a behaviour that looks cute when the children are younger has the potential to look aggressive and threatening when they are bigger.

Siblings become aware of the differences related to disability partly through experiencing other people's attitudes in their comments and actions. Feeling that their sibling with a disability is not being understood or respected can thrust a child into the situation of having to advocate for themselves and their sibling. Examples of situations where siblings feel called upon to advocate can be subtle, as when a child with disability incidentally misses out on an event or experience, or more glaring, such as being intentionally excluded from participating. It can be experienced when there is an omission of gift-giving for the child with disability though the other children in the family receive something, or when there is a phone call ahead of a social event to determine if the child with disability will be attending and what concessions will need to be made for them.

The issues giving rise to advocacy may come up at points of social conflict for the siblings. Whether a sibling responds outwardly or not, these issues can cause distress for the sibling and may need a follow-up conversation or two.

While advocacy may become part of the sibling's role, it is, of course, not possible for them as disability advocates to right every wrong or to make every uncomfortable person feel 
International Journal of Child, Youth and Family Studies (2018) 9(4): 75-87

less uncomfortable in their limited awareness of disability. Siblings have no special powers, yet from a young age there seems to be an expectation that they can handle such situations with a few choice words. Advocacy needs to be taken on by others, not just siblings, and words alone are not enough — matched actions are required.

To show people how to be comfortable with disability and how to have high expectations of others is something that can be modelled by anyone. One must be guided by what a person with disability can do and not what one thinks they cannot do. Misguided assumptions are usually somewhere at the bottom of every awkward disability-related interaction. While it can be useful to highlight people's assumptions and help develop their understanding, there will be other times when it is best for the advocate to just maintain composure and walk away.

For example, a sibling was walking out of a funeral service with her sister with disability when a woman behind her tapped her on the shoulder to tell her that people like her sister were usually killed at birth. The sibling maintained composure and moved on. In another instance, a sibling heard derogatory comments from a relative about people with disabilities and reminded the person that she had a sister with a disability, who was also the other party's cousin. A sibling may be stopped in the street by someone who praises their selflessness for working in the disability field, when in fact they are just out for a walk with their brother — no payment involved.

\section{The Power of Inclusion}

Growing up, it was clear to me that disability was not just in my family. However, as we went about our day-to-day lives, most of the disability we saw was related to our disabilityspecific activities like therapy and special school events, places where it is routine to encounter a high proportion of people with a disability. This did not carry over into the everyday world of shopping or catching the bus to school.

In primary school my class put on a show for all the parents and friends, and I recall being almost mesmerised by a young boy in a wheelchair. Here was a child with a disability whom I had never heard about, let alone seen, and here he was at our play to see his sibling perform. It struck me that I had not seen this child before now, even though they lived close to the school and were part of the wider school community. Seeing that child gave me a sense of connection, that after all it was not just me and my sister in my local community. Even though we had completely different experiences - there was no way my sister would have stayed quiet through a school play, let alone sat still for it — it affected me powerfully.

Over the years many parents have brought their children over to me and told them that I also have a sibling with a disability. Although it is done in the kindest of ways to connect siblings and let them know they are not alone in their experiences, it usually ends the conversation right there as there is often not much you can say after that. The most valuable 
International Journal of Child, Youth and Family Studies (2018) 9(4): 75-87

sibling connections for me have been the incidental ones where you find out about people through seeing them out and about with their families, or through a disclosure in conversation.

In my experience through planned and unplanned events, this has been a consistent factor. Siblings do not get together simply because they are siblings; rather, they get together around shared activities that may not even include any discussion of disability. The understanding of siblings comes from the context of seeing the sibling with the child with a disability. That promotes the feeling of a shared experience better than any conversation.

\section{Being Prepared}

Families can make strategic decisions about what events they want to participate in, and what conditions they are prepared to put their family members through. For example, a casual backyard barbeque where the child with a disability can pace along the fence line may sound fine, but a formal three-course birthday dinner might not be worth the stress. That said, it is not about avoiding certain situations, but thinking about what to do if the evening does not unfold as planned. Will there be somewhere for the child to withdraw to if needed? Is the car parked somewhere it can be used as a retreat?

Families who manage social outings well usually have a level of planning embedded in the background. This can be anything from a change of clothes or two, items of interest to distract or amuse in necessary moments, drinks and snacks, or even a previsit to scope out the location. Being prepared is as much about turning up ready for the event as it is about carefully picking and choosing the events that are worth planning for. A big noisy fair with a child who likes to vocalise might be a better choice than a packed movie theatre where everyone expects audience members to remain generally quiet.

On a more practical note, for social events where a change of clothing is likely to be required due to incontinence or messy eating, preparations can include having a few identical clothes on hand so that one can change an older child without having to obviously change outfits. Most people would not even realise the clothing has been changed, and any embarrassment the child or siblings might have felt around the need to change clothing is thus avoided.

\section{Adolescence}

Adolescence can be a difficult time for both child and parent, even without the experience of disability: independence is being sought, parents can be embarrassing, and the peer perspective can be critical. Although adolescents may appear to be uninterested, or unwilling to talk, they are still taking in information and trying to make sense of their emerging adult world. Questions about their sibling's future can come up around family supports, finances, and accommodation choices. At the same time, adolescents can get very sensitive about their public profile and how they are seen by others. It can be a time when they seek more distance from their sibling with disability, and can feel put-upon by requests to help out. 
International Journal of Child, Youth and Family Studies (2018) 9(4): 75-87

In the continuation of the disability discussion that started in early childhood, questions about family genetics and heredity can come up, as well as the issue of future partners and how they will respond to or cope with the sibling with disability. This can also be a good time for parents to consider one-to-one catch-ups with siblings such as a movie day or a special outing that gives full attention to the sibling, and gives the parent an opportunity to explore the sibling's perspectives, using the distraction of other activities to facilitate the conversation. Riding in the car also provides occasions when such communications may take place: talking side-by-side during a drive can be less confronting than face-to-face conversation.

As children grow older they begin taking on more responsibility and having more freedom of choice. This is true for both the sibling with disability and the one without. This change needs to be considered and planned for as belonging to a continuum of learning and development, as turning 18 will not magically bring about the ability to function as an independent adult. The planning of what adulthood needs to look like is a process that starts in childhood for all siblings and especially when there is a child with a disability.

\section{Adulthood}

As siblings move into adulthood the relationship dynamics can change. Living circumstances can shift and parents getting older might require more support themselves. It can be a difficult time to navigate when there is a sibling with disability and a shift in caretaking responsibilities. This is a time when open conversations are needed about each family member's expectations, their understanding of the reality of the current situation, and their views on what practical steps are possible.

In all my years of speaking with parents there have been many different expectations of adult siblings. For some parents there is no question that the sibling will step up to provide care, from financial oversight through to opening their family home and being full-time carers. Other families might want the sibling to have nothing to do with day-to-day needs and want to make sure that the sibling is not burdened with providing any support, to the point that the sibling might be excluded from conversations touching on those topics.

No matter what the parents' expectations are, the most important question to ask of parents is what their children's expectations are. Many times I speak with parents who have a clear plan set out for their child with a disability, but they are less clear about having spoken with their other children and having their agreement to the plan.

It is a balancing act, as parents will at some point need to relinquish some of the decision making and control to siblings, and siblings need to be clear about what they are prepared to take on. For some families this is an open conversation from early on, while others might need a formal facilitator to have a productive conversation where everyone can be heard. 
International Journal of Child, Youth and Family Studies (2018) 9(4): 75-87

\section{Professionals}

Families are dynamic and unique in how they function. As professionals going into family homes and sometimes seeing families at their worst, it is a privilege to have families so openly share their stories and dreams for the future. In order to provide relevant advice and support for the family, professionals need to be curious and nonjudgemental when trying to understand the family's current reality and key priorities. In asking about the family, professionals must consider the siblings. If they are too young to give their own perspectives, then they can be observed interacting with their sibling with disability.

There are as many similarities as there are differences when you consider any two families. What is really important to remember is that most families are doing the best they can based on what they consider to be the best choices for them. As professionals we can offer an open and non-judgemental perspective to families, which can help them to gain an oversight of the current situation and see opportunities that are not always as easily spotted from up close.

For example, a mother who was having a struggle to get her child with disability ready for school each morning decided the solution was to ask for respite care. From the professional perspective, it was apparent that this mother had a very busy morning routine that the children were all being pushed through and it was creating tension between the siblings as they were often late to school. A respite option would have provided some support in the moment but would not have had any impact on the long-term needs of the family. Instead, a morning routine was developed for the family so that everyone had their own schedule of activities. This created a new skill set for the child with disability, which reduced the family stress, improved the sibling relationship, created more time in their morning, and got the children to school on time. This was a more sustainable and meaningful outcome for the whole family.

Sometimes the advice needs to be about what can work right now for a family when they do not yet have the physical, emotional, or financial space to think about and work towards a long-term solution. Being non-judgemental is critical to hearing a family's story and trying to ascertain where they can find opportunities that fit with their priorities and resources. If a family is worried about finances they are unlikely to want to talk about sibling relationships, but if the focus can be about free activities they can easily get to on the weekend, it might be a conversation they are ready to have.

When we are on the outside looking in it is easy to get carried away with ideas of what can happen for families, but for families change can be a very slow process, and it can often be about waiting for the right time to introduce an idea or discuss different approaches.

There are some simple ways to help siblings without disability feel included. With younger siblings, it can be letting them borrow their own toy from the toy library, giving them a choice of play activities to help shape a therapy session, or asking their assistance to set up a game for their sibling with a disability. For older children it can be about giving them more 
International Journal of Child, Youth and Family Studies (2018) 9(4): 75-87

information about decision-making or just asking for their perspective as part of the conversation.

\section{Concluding Remarks}

Quality of life research has been important in understanding the impact a child with a disability has on family dynamics. In turn, the sibling perspective has been an equally important consideration for understanding family quality of life. The impact for siblings is contextualised in the sibling relationships; as the most enduring relationship for a person with a disability, it is important that it is strengthened and supported from the early years and into adulthood. 
International Journal of Child, Youth and Family Studies (2018) 9(4): 75-87

\section{References}

Brown, R.I., MacAdam-Crisp, J., Wang, M., \& Iarocci, G. (2006). Family quality of life when there is a child with a developmental disability. Journal of Policy and Practice in Intellectual Disabilities, 3(4), 238-245. doi:10.1111/j.1741-1130.2006.00085.x

Limbers, C. A., \& Skipper, S. (2014). Health-related quality of life measurement in siblings of children with physical chronic illness: A systematic review. Families, Systems \& Health, 32(4), 408-415. doi:10.1037/fsh0000077

Luijkx, J., van der Putten, A. J. \& Vlaskamp, C. (2016). "I love my sister, but sometimes I don't": A qualitative study into the experiences of siblings of a child with profound intellectual and multiple disabilities. Journal of Intellectual and Developmental Disability, 41(4), 279-288. doi:10.3109/13668250.2016.1224333

Wofford, J. R. \& Carlson, R. G. (2017). A literature review and case study on the strengths and struggles of typically developing siblings of persons with disabilities. The Family Journal: Counselling and Therapy for Couples and Families , 25(4), 398-406.

doi: $10.1177 / 1066480717732167$ 